\title{
EQUIDADE: APONTAMENTOS PARA A EDUCAÇÃO DO CORPO
}

\author{
MS. SISSILIA VILARINHO NETO \\ Doutoranda em Educação pela UFG e Professora Assistente da Faculdade de Educação \\ Física da Universidade Federal de Goiás (Goiás - Brasil) \\ e-mail: vilasissilia@yahoo.com.br
}

\begin{abstract}
RESUMO
O propósito da exposição é analisar o desenvolvimento histórico da idéia de igualdade e seus desdobramentos em políticas de equidade. Durante a estruturação e desenvolvimento da sociedade capitalista, observa-se a tensão histórica pela igualdade substantiva e as elaborações científicas e políticas para viabilizar um sentido de igualdade subjetiva, fundado em bases biológicas, a partir da qual se forma o indivíduo que tem na sua constituição corporal, a igualdade que the garante participação social. Hodiernamente, as políticas de equidade dão continuidade ao sentido histórico de igualdade proposto pela sociedade capitalista, ao eleger a diferença como princípio capaz de realizar a efetiva igualdade de oportunidades.
\end{abstract}

PALAVRAS-CHAVE: Equidade; igualdade; diferença; corpo.

O processo educacional real e histórico do corpo tem colocado em evidência o trato com a inclusão de indivíduos que, por suas diferenças físicas, há pouco tempo eram considerados ineficientes ou incapazes de contribuir com a sociedade. Tais indivíduos são mulheres, negros, indígenas, portadores de deficiências, homossexuais etc. 
As promessas não realizadas pela lógica social desigual do atual modo de produção têm acirrado as contradições inerentes ao sistema, demandando reformas que potencializem a continuidade dessa forma de produzir a vida.

Dentre as inúmeras reformas, as políticas de equidade têm objetivado minimizar os processos de marginalização dos indivíduos. Intrinsecamente a elas, encontra-se o princípio jurídico da igualdade e o sentido de viabilizar a tão almejada igualdade social.

Em que medida isso se viabiliza tomando o indivíduo e suas particularidades corporais como eixo central é objetivo desse texto.

\section{CIÊNCIA POSITIVISTA: APORTE TEÓRICO PARA LEGITIMAR A APOLOGIA DA IGUALDADE}

Ao abordar o tema da equidade no conjunto das reformas políticas atuais, implícito está o princípio revolucionário da igualdade e fundamental é acompanhar os desdobramentos desse princípio na sociedade capitalista.

O princípio da igualdade, a partir do século XVII, constitui-se como produto histórico do processo de reposicionamento do homem frente à vida em sociedade. Compôs fundamentalmente o projeto de sociedade moderno ao qualificar os homens como seres racionais, autônomos e livres; capazes de promover o progresso, o bem-estar e a felicidade de todos indistintamente. Igualar todos seres humanos foi revolucionário e ainda hoje carrega esse sentido, especialmente em contextos marcados por aberrantes desigualdades sociais.

O tema da igualdade é readequado ao contexto revolucionário europeu ganhando destaque no movimento filósofico-científico da época. Tal movimento foi uma força fundamental para o processo de justificação ideológica da revolução (FERRONE, 1997) e, inclusive, para os desdobramentos políticos e sociais da idéia de igualdade no pós-revolução.

Como reação à posição que tinha como poder central o teo determinando inquestionavelmente a condução da vida, estruturou-se outra compreensão ontológica para a existência humana. Com Descartes, a razão tornou-se a capacidade de discernimento entre o verdadeiro e o falso. Elemento diferenciador do homem e dos outros animais, a razão foi a possibilidade da liberdade de conhecer e, por conseqüência, do agir humano sobre a natureza e seu dinamismo.

O pensamento cartesiano supervalorizou a capacidade racional de conhecer os vários objetos disponíveis na natureza, inclusive o próprio corpo humano. Para que todos igualmente chegassem à verdade, colocou à disposição da humanidade o método e o pressuposto de funcionamento mecânico de toda a natureza. 
Locke também estabeleceu uma lógica racional para a igualdade. Em consonância com as demandas do real, o filósofo do empírico ressignificou o princípio da igualdade baseado na razão. Para Locke a razão tem raízes na experiência. Dessa forma, a igualdade é viabilizada pela experiência. Na perspectiva empiricista lockeana, a definição da natureza humana passa pela equiparação do ser humano aos outros animais. Locke defendeu que a natureza humana é regida pela autopreservação e preservação da espécie. O elemento diferenciador é a racionalidade. Essa possibilita ao homem influenciar, interagir e transformar o mundo.

Um suposto Estado Natural do homem coloca todos em condições de igualdade racional para exercer sua liberdade (LOCKE, 2006). Todos são dotados de liberdade, logo são iguais para exercer sua liberdade. Porém, o exercício racional da liberdade está condicionado aos limites individuais da experiência humana e da capacidade de juízo e de decisão perante as coisas que lhes são postas. A razão não é perfeita e é contingente à experiência. "Mas com todos os seus limites e as suas imperfeições, a razão é, segundo Locke, o único guia de que o homem dispõe em todas as circunstâncias da vida" (ABBAGNANO, 2000, p. 175).

O Estado Natural idealizado por Locke é parâmetro para orientar a realidade organizada pelas características individuais da perspicácia, competição e individualidade. A propriedade de bens é justificada a partir do próprio indivíduo que tem o seu corpo como primeira propriedade e é dotado de consciência sobre as suas ações e os resultados dela. É por meio do elemento material que se dá toda a ação humana na natureza. Natureza modificada agrega uma espécie de identidade do indivíduo que a modificou, mas o indivíduo deve ter consciência de que essas modificações trarão benefícios para a sociedade, gerando um sentido de reciprocidade (cf. LOCKE, 2006).

Arraigado no pensamento desse autor está a perspectiva evolucionista de desenvolvimento econômico, amparada por especulações sobre as condições de vida em diferentes sociedades registradas por viajantes e por estudos históricos de sociedades antigas. Há, também, o desenvolvimento de certa lógica para justificar a divisão do trabalho. Essa lógica funda-se na defesa de que uma economia de base coletivista, a partir da qual o homem foi progredindo a uma experiência econômica em que os indivíduos, por meio de sua racionalidade, foram capazes de se promoverem, gerando benefícios individuais e sociais. Cada indivíduo, com suas potencialidades e a partir das possibilidades de exercitá-la, seria responsável pela sua condição e posição sociais.

modelo de pensamento supramencionado contribuiu para a formação de consenso em torno de uma perspectiva de justiça social fundada no interesse e potencialidade individuais como promotor de progresso para todos indiscrimi- 
nadamente. Não é possível progredir sozinho sem que isso traga algum benefício para a sociedade. Esboçou-se, pois, um sentido universal de justiça social, pautado na ética e moral do indivíduo.

As contradições, que começaram a ser evidenciadas com a instauração da sociedade capitalista, colocaram em questão a eficiência dos governos e a viabilidade da sociedade regida pela liberdade entre todos e por uma justiça formal e abstrata. A criação de ações políticas com a perspectiva de reformar e estabilizar o sistema se deu, em certa medida, influenciada pela ciência positiva. Ciência essa que produzia explicações e ações para resolver os males que inviabilizavam o progresso da sociedade e de todos os indivíduos.

A idéia do homem europeu livre, dotado da capacidade de agir racionalmente na condução da sua vida, associada ao desenvolvimento da engenharia (de navegação), da química e da física foram elementos fundamentais para orientar os projetos políticos de exploração e colonização do mundo. As campanhas de exploração de outros territórios, orientadas pelo olhar da ciência positivista, teve por finalidade observar, comparar, classificar não somente elementos da natureza e também o próprio homem.

Mas os exploradores, quando vão até aos confins do mundo, têm em mente outros esquemas para além da recolha naturalista. O primitivismo dos filósofos que, de Buffon a Rousseau, de Helvétius a Diderot, apresentam o selvagem como testemunho das origens do homem, está subjacente à percepção e à atitude dos navegadores perante aquilo que descobrem. As anotações dos seus diários revelam como a deslocação no espaço é vivida como uma viagem no tempo que conduz a épocas primeiras da humanidade. Para Bougainville, a escala taitiana assinala a consecução deste regresso ao passado, aos tempos das origens: aqui encontra um povo «que traz para as artes aqueles conhecimentos elementares suficientes ao homem que vive próximo ao estado natural, que trabalha pouco, que usufrui de todos os prazeres da sociedade, da dança, da música, da conversa e, enfim, do amor, o único deus ao qual creio, este povo se sacrificará». Para o europeu, a viagem proporciona a ocasião de um regresso às origens da história humana (BOURGUET, 1997, p. 235-236).

$\bigcirc$ progresso da sociedade subordina-se à capacidade do homem como indivíduo e suas potencialidades genética e naturalmente estabelecidas. É a natureza que determina o desenvolvimento individual e, por conseqüência, social. A ciência se debruçou sob esse aspecto para compreendê-lo e depois dar-lhe a direção. Conforme Soares (200 I, p. 16),

todas as desigualdades sociais [...] tomam, assim, a aparência de diferenças hereditárias, genéticas, portanto, naturais, transmitidas de geração a geração, sem possibilidade histórica de serem alteradas. Afinal, são as pesquisas científicas que 'demonstram', pelos dados apresentados, esse quadro absolutamente inalterável. 
trato social com as diferenças físicas foi sendo constituído na luta pela igualdade social entre os homens. Desde o século XVII, o corpo humano, na sua imediaticidade, como coisa estranha face às relações fetichizadas e reificadas com a sua produção e consigo mesmo, foi sendo tomado pelas ciências biológicas como objeto de investigação. Ao mesmo tempo em que se atribuía aos homens um sentido de igualdade física, como pode ser observado em La Metrie com a sua concepção de corpo-máquina (ROUANET, 2003), eram realizadas investigações biométricas para classificar, qualificar e exterminar indivíduos por sua origem seja sexual, étnica ou geográfica, como observa-se na produção de Francis Galton (DEL CONT, 2008).

As ciências biológicas contribuíram para justificar por leis naturais, ora a igualdade, ora as desigualdades advindas das diferenças orgânicas ou diversidade biológica. Nas investigações biológicas sobre o corpo humano o que se torna mais visível, potencialmente progressivo ou regressivo, é o elemento biofísico de cada indivíduo. O indivíduo, que desde o Renascimento é racionalmente considerado livre e capaz de influenciar, interagir e transformar o mundo, passa a ser responsabilizado pela sua constituição orgânica que interfere no seu sucesso ou fracasso.

Tornando visível o que não é, as investigações microbiológicas expuseram que o que o indivíduo é, não é determinação social, tão menos divina; mas determinação natural. A tentativa de explicar a realidade sob a ótica do invisível, reforçou-a no seu aspecto aparente, vez que a essência de determinada coisa passa a ser a coisa mesma nos seus elementos microscópicos. A realidade contraditória, excludente, injusta passa a ser concebida como irrealidade, pois o que se torna real, visível, é o elemento biofísico de cada indivíduo.

Para Soares (200 I ) e Silva (200 I), isso possibilitou outra experiência corporal para o homem com conseqüências sociais mundiais. As investigações anatômicas, fisiológicas e microfisiológicas muitas vezes sustentaram explicações ideológicas sobre desigualdades sociais locais e político-geográficas,a partir da avaliação da composição corporal do indivíduo - nos elementos visivelmente expostos (cor da pele, estatura, sexo, caixa craniana) e nos elementos não visíveis a "olho nu" (DNA, genética, funcionamento celular, volume cerebral). Permitiu, ainda, racionalizar o corpo do trabalhador tornando-o produtivo e integrado ao conjunto produtivo da sociedade (HEROLD JUNIOR, 2009).

Das idéias de que todos, originariamente, são iguais por que livres e dotados de razão, passou-se à idéia de que, apesar de iguais, os homens são diferentes na sua constituição biológica e isso se torna determinantes para o surgimento e desenvolvimento de diversas formas de usar a liberdade na construção de modos particulares de vida social. 
Diante da inviabilidade social do princípio de igualdade de oportunidade a partir da competência única e exclusiva do indivíduo, foi inevitável restaurar/reformar a lógica do sistema recuperando o próprio indivíduo como elemento a ser reajustado. Otimizar a máquina humana foi, então, objetivo de projetos políticos estatais sanitaristas que - na Europa do século XVIII, início do XIX - numa perspectiva educativa, alcançaram a família, a fábrica, o exército, a escola, a organização espacial e a arquitetura da cidade (COSTA, 1999; SOARES, 200 I). Os projetos sanitaristas buscaram estabelecer nos indivíduos hábitos saudáveis e produtivos integrando-os ao organismo social vivo. ${ }^{1}$

Insistir num sentido de igualdade focado no indivíduo foi fundamental para garantir os ares revolucionários impulsionadores do processo de implementação do modo de produção capitalista. Entretanto, esse princípio tem demonstrado sua inviabilidade econômica e política. O próprio Estado teve que atuar no sentido de sanar os chamados desequilíbrios sociais advindos da experiência de liberdade vivida pelos indivíduos nos diversos contextos nacionais.

Hodiernamente, os desdobramentos da idéia de igualdade construída pelo movimento iluminista ainda colocam questionamentos sobre a essência dessa forma de organização social e desafios políticos para a sua continuidade. Uma das formas de resolver os impasses postos por essa forma de ver, compreender e atuar do homem é a justaposiçãa do termo equidade ao igualdade e, em alguns casos, substituição do segundo pelo primeiro. A substituição não significa um "novo iluminismo". O sentido da idéia de igualdade permanece, mas reformado ante os desafios humanos postos para o modo de produção da vida do capital.

\section{EQUIDADE E AS DIFERENÇAS COMO QUESTÃO DE JUSTIÇA SOCIAL}

Equidade é uma palavra cuja origem etimológica remete à justiça no aspecto moral e ético do direito em uma dada sociedade (HOUAISS; VILLAR, 200I). Está no plano da operacionalização do sentido liberal do princípio de igualdade.

Nas sociedades democráticas neoliberais, a equidade visa fornecer orientação filosófica e moral para as instituições democráticas, partindo do pressuposto de

I. De acordo com Góis Junior e Lovisolo (2003), as políticas sanitaristas continuam em voga, com apropriações e ressignificações para se ajustar ao atual momento histórico. É considerado um movimento reformista, criador de mecanismos de ocultamento das contradições da sociedade, responsabilizando o indivíduo pelo seu sucesso ou fracasso social. Assumiu ora uma intervenção higiênica, ora eugênica, e as duas de forma combinada. 
que as normas genéricas - igualdade de oportunidades - devem ser adequadas a contextos específicos.

Na obra "Por uma Teoria da Justiça", 2 a palavra equidade tem o sentido de ajudar a formar um esquema justo de ordenação social: um "esquema de cooperação" para a vantagem de todos (RAWLS, 2002, p. 80). Como a idéia de equidade demanda levar em consideração as desigualdades dos casos para assim fazer justiça, Rawls defende que não é possível ser justo a um indivíduo ou grupo prejudicando outros, mesmo que aqueles a quem esteja sendo feita a justiça sejam menos favorecidos do ponto de vista do acesso aos bens sociais primários (direito, liberdade, oportunidades, renda e riqueza).

A sociedade deve ser ordenada juridicamente de tal forma que possibilite o crescimento de todos, viabilizando uma "ligação em cadeia": na medida em que os menos favorecidos se beneficiam, o mesmo acontecerá com os mais favorecidos. Nessa acepção, elimina os problemas relacionados à eficácia social do sistema produtivo, que se localizam numa justiça injusta, a qual não considera o fato de a igualdade de oportunidades não ser viabilizada igualitariamente, por que os indivíduos estão em posição social desvantajosa em relação à lógica produtiva.

A teoria da justiça rawlsiana tem por fim ordenar a "estrutura básica" - sistema público de regras - na atribuição de direitos e deveres às instituições sociais, determinando a distribuiçã̃o adequada dos benefícios e encargos da vida social.

Buscando operacionalizar a justiça pautada pela observância das desigualdades sociais, Rawls (2002) apresenta um novo princípio: da diferença. O princípio da diferença não é um princípio de reparação, mas sim de reciprocidade; pois não se pode oferecer vantagens a um grupo de indivíduos apenas. Independentemente da condição social em que o indivíduo se insere, o sentido de reparação coloca em prejuízo outro grupo. Já o sentido de reciprocidade carrega o princípio de fraternidade, com um senso de amizade cívica e solidariedade social.

O princípio da justiça, entretanto, parece corresponder a um significado natural de fraternidade: ou seja, à idéia de não querer ter maiores vantagens, exceto quando isso traz benefícios para os outros que estão em pior situação.

[...] Uma vez que aceitarmos, podemos associar as idéias tradicionais de liberdade, igualdade e fraternidade com a interpretação democrática dos dois princípios da justiça da seguinte maneira: a liberdade corresponde ao primeiro princípio, a igualdade à idéia de igualdade no primeiro princípio juntamente com a igualdade eqüitativa de oportunidades, e a fraternidade corresponde ao princípio da diferença (RAWLS, 2002, p. I | 2- | I3).

2. Primeira edição: 1971. 
O princípio da diferença é um princípio que respeita as diferentes posições sociais e viabiliza a democracia da sociedade pautada pela igualdade de liberdades na economia de mercado livre.

A primeira crítica a ser feita a esse pensamento circunscreve-se ao "esquema de cooperação social". "Cooperação social" carrega um apelo humanitário, que em última instância parece ontológico ao recuperar relações de reciprocidade que os homens estabelecem para produzir a vida. Mas o que ocorre é adequação do pensamento à lógica da instrumentalização das relações sociais com a finalidade de tornar mais eficiente o sistema produtivo, validando não a relação entre os homens, mas a relação entre as coisas. A finalidade é manter o funcionamento sociometabólico do capital.

A segunda crítica é sobre a idéia de igualdade equitativa que toma a diferença como ponto de sustentação e parâmetro para tratar o desigual. Pierucci (1999), na obra de título sugestivo: "Ciladas da diferença", recupera a construção histórica da diferença para afirmar que a defesa dessa surge do movimento conservador ultradireitista.

Para ser historicamente mais exato, foi a ultradireita do final do século XVIII e primeiras décadas do XIX, aliás a primeira direita a surgir na História, em reação à Revolução Francesa, ao ideal republicano de igualdade e fraternidade e a tudo quanto de universalismo e igualitarismo havia no movimento das idéias filosóficas do século XVIII (PIERUCCI, 1999, p. 19).

Houve, naquele contexto histórico, um movimento de negação a qualquer universalismo igualitário por entender que estes partiam de uma concepção abstrata do mundo, negando as diferenças históricas.

A focalização da diferença parte do que é imediato e incontestável e nele mesmo se fixa, sem pretensão de compreender os fundamentos, os nexos e os significados disto para a sociedade. Assim, nega-se e afirma-se as diferenças por elas mesmas, a partir da observação do plano biológico, dando os elementos para consolidar a lógica de biologização do pensamento social (PIERUCCI, 1999). Diferenças constatadas empiricamente no plano biológico surgem como argumento para estabelecer diferenças sociais.

Se o princípio de igualdade de oportunidades já carregava em si o germe da perpetuação das desigualdades sociais e sua legitimação no plano biológico e restrito ao indivíduo, o princípio da igualdade equitativa de oportunidades apenas torna esse aspecto evidente, fatídico e verídico; fato dado socialmente que necessita, apenas, tornar-se menos injusto para aqueles que geneticamente estão colocados marginalmente na sociedade. 
A exaltação da diferença ganha força e evidência a partir dos anos de 1970 (PIERUCCI, 1999). Em decorrência dos processos de democratização de vários países, das lutas pelos direitos humanos, da dinâmica de expansão do capital, da valorização da diversidade cultural dos povos, do crescente interesse da mídia pela aparência do corpo, dentre outros, também os movimentos sociais - tanto de direita quanto de esquerda - focalizam as diferenças objetivando ou minimizar ou superar os grotescos problemas de desigualdades a partir da garantia de direitos que viabilizam a inserção e participação em espaços sociais considerados promissores do acesso às benesses da sociedade.

De acordo com Pierucci (1999), a perspectiva histórica, moral e política da idéia de diferença consubstancia a falácia dos projetos revolucionários que se articulam em torno da defesa do não igual, dos excluídos, pretendendo a igualdade. Esses projetos se inserem num movimento de reformismo social.

Nessa perspectiva, Rawls (2002) - apesar de reconhecer que o processo de biologização social afetou a promoção da justiça social - conjectura que para viabilizar a equidade da forma mais justa é necessário considerar os lugares de partida dos indivíduos para a competição social. Esses lugares determinam a forma como cada um fará uso das oportunidades que estão postas.

Assim, para esse autor, a valorização das diferenças significa investimento na auto-estima - bem primário essencial a partir do qual haverá ordenamento positivo das instituições sociais. Conquista-se a auto-estima na medida em que o indivíduo torna-se capaz de contribuir de forma eficiente com o sistema de cooperação social. Para tanto, é fundamental que ele reconheça seus "dotes naturais" e eles sejam potencializados.

Não vou considerar questões de eugenia, limitando-me ao longo de todo este trabalho às preocupações tradicionais da justiça social. Apesar disso, deveríamos notar que, em geral, propor políticas que reduzem os talentos dos outros não traz vantagens para os menos favorecidos. Por outro lado, uma vez que se aceita o princípio da diferença, as maiores habilidades são consideradas como um bem social a ser usado para o benefício comum. Mas também é do interesse de cada um ter maiores dotes naturais. Isso permite que as pessoas busquem um plano de vida preferido. Na posição original, então, as partes querem assegurar para seus descendentes a melhor dotação genética (pressupondo que a sua própria seja fixa). A busca de políticas razoáveis com respeito a isso é algo que as gerações anteriores devem às posteriores, sendo essa uma questão que surge entre gerações. Assim, ao longo do tempo, uma sociedade deve tomar atitudes para pelo menos preservar o nível geral de capacidades naturais e impedir a difusão de defeitos graves. Essas medidas devem ser guiadas por princípios com os quais as partes estariam dispostas a concordar para o bem de seus sucessores (RAWLS, 2002, p. I I5). 
Se todos, mesmo sendo diferentes, são iguais para, no exercício das suas liberdades, contribuírem com o "esquema de cooperação social" rawlsiano, então é mister continuar atuando na recuperação produtiva da "máquina" humana.

Essa parece ser a lógica racional que acompanha o discurso da equidade no campo das políticas de saúde e, em particular, da educação. As instituições sociais que viabilizam a equidade devem "otimizar" os indivíduos menos favorecidos, para gerar bem-estar e força produtiva.

Com esse delineamento, organismos multilaterais como o Banco Mundial têm definido diretrizes para o estabelecimento de políticas para os países em desenvolvimento, onde o índice de miséria é grotesco.

Para o Banco Mundial, as injustiças sócio-econômicas cometidas com os indivíduos em função da suas diferenças étnicas e de gênero "podem levar à perda do potencial humano e, portanto, à perda de oportunidades de desenvolvimento" (BANCO MUNDIAL, 2006, s. p.). A implementação da equidade visa garantir "oportunidades iguais de buscar a vida que desejam e serem poupados de extrema privação de resultados". "Mais equidade é, portanto, duplamente útil para a redução da pobreza: por meio de possíveis efeitos benéficos para o desenvolvimento de longo prazo agregado e por intermédio de mais oportunidades para os grupos menos favorecidos dentro de qualquer sociedade" (BANCO MUNDIAL, 2006, s. p.).

No contexto global e neoliberal, o Banco Mundial promove e dissemina projetos e programas pela maior quantidade de países, especialmente os países localizados na região sul do globo. Coraggio (1998, p. 85) explica que o sentido de equidade presente nos documentos do Banco Mundial remete ao desenvolvimento de estratégias para evitar conflitos entre os interesses dos pobres e dos ricos; o que poderia gerar situações e ambientes de instabilidade e de desconfiança pública. As diretrizes do Banco tem dois componentes: I. promover o uso produtivo do trabalho dos pobres e 2. fornecer aos pobres os serviços sociais básicos: saúde primária, planejamento familiar, nutrição e educação primária.

Esta proposta estratégica para atacar a pobreza explicaria porque o Banco Mundial, que, tradicionalmente, direcionou investimentos para a infra-estrutura e o crescimento econômico, aparece cada vez mais como uma agência propulsora do investimento em setores sociais e na reforma do conjunto de políticas sociais. Trata-se de prevenir situações politicamente críticas (CORAGGIO, 1998. p. 86).

Na medida em que "o objetivo não é a igualdade das rendas, mas a expansão do acesso, por parte das pessoas de baixa renda, aos cuidados da saúde, educação, emprego, capital e direitos de posse da terra" (BANCO MUNDIAL, 2008, s. p.); evidentemente, na medida em que não se trata de transformar a sociedade, e sim 
de reformá-la, é necessário, pois, que os indivíduos consintam com a continuidade da lógica da exploração e da inclusão-excludente.

A forma de conquistar esse consentimento passa por um processo de instrumentalização da inteligência dos indivíduos, usando-a com a finalidade de garantir participação focal e pragmática, limitada à resolução de problemas focais.

As áreas científicas da biomedicina, da psicologia comportamentalista e físico-computacionais têm desenvolvido estudos acerca do denominado "corpoinformação". Estes estudos vêm de uma demanda relacionada à integração mecânica dos indivíduos na lógica produtiva de bens e serviços e alcança outros espaços da vida social. Trata-se de estudos que usam a inteligência artificial e a psicologia para instrumentalizar o pensamento e otimiza-lo no processo produtivo. É um processo combinado de exploração da inteligência prática do trabalhador, com a garantia do envolvimento deste na produção. Isso gera "o envolvimento individual na realização das mais variadas tarefas e que está intimamente conectada com a construção de uma auto-imagem perante o mundo" (HEROLD JUNIOR, 2009, p. I I 7).

Essa forma de participação é adquirida por um processo educacional que visa minar a dinâmica de construção das formas de participação coletiva. Nos documentos do Banco Mundial, os indivíduos menos favorecidos devem desenvolver competências para a participação nos processos de otimização das oportunidades objetivando garantir suas capacidades concorrenciais. $\bigcirc$ desenvolvimento dessas competências passa pelo processo de empowerment ${ }^{3}$ dos indivíduos.

Conforme o Banco Mundial (2006, s. p.), "Empowerment é a expansão de vantagens e capacidades (ou habilidades) de pessoas pobres para participar, negociar com, influenciar, controlar e sustentar incontáveis instituições que afetam suas vidas".

Empowerment, associado à idéia de igualdade equitativa de oportunidades, significa valorização das diferenças biológicas e sociais. Stotz e Araújo (2004, p. 14) afirmam que o empowerment remete a um tipo de participação.

Empowerment, contudo, não é visto como meio de fortalecer a ação coletiva contra as estruturas de poder. Para expressar a teoria social implícita, empowerment é um método

3. De acordo com Stotz e Araújo (2004, p. 13), "empowerment é uma palavra da língua inglesa sem tradução para a nossa. Uma tradução do verbo empower oferece os sentidos de autorizar, de habilitar ou permitir. O sentido de habilitar, tornar hábil, apto, prover de conhecimentos pode ser interpretado nos temos de capacitação, mas há uma recusa em admitir o sentido de que dê alguma transferência entre sujeitos. Tem sido traduzida pelos neologismos de apoderamiento (espanhol) e empoderamento (português, espanhol), sem significado dicionarizado entre nós. Preferimos usar a palavra na língua inglesa porque [...] insere-se na tradição anglo-saxônica do liberalismo civil e religioso e, com isto, não apaga a sua marca de origem". 
de construção de consenso que exige negociação e concertação social. É o que acontece nos Estados Unidos, onde agentes sociais buscam o consenso capaz de reunir fuerzas de ciudadones para llevar sus quejas, reclamos e inquietudes al gobierno y que este los tuviera em cuenta em las políticas. Esses processos de negociação e de concertação social requerem métodos de participação e "empoderamento" (STOTZ; ARAÚjO, 2004, p. 14).

O processo educativo que articula empowerment e equidade pautada pela diferença, tem em vista a conscientização dos problemas postos pela participação, descoberta de habilidades e competências para atuação a partir das suas diferenças (étnica, gênero, patologia etc) e negociação para resolver problemas específicos como se fossem problemas universais. Esse processo educativo integra os indivíduos na sociedade como um humanware ${ }^{4}$, concebendo seus diferentes corpos como funcionais à produtividade do sistema.

\section{CONSIDERAÇÕES FINAIS}

Ao analisar as questões postas pela equidade, identifica-se a sua íntima relação com o movimento histórico que atribui sentido à idéia de igualdade no capitalismo. Ao tomar as diferenças corporais como questão de justiça social e atribuir potencial para reverter questões de desigualdades sociais, nota-se que os princípios que norteiam as políticas de equidade para os países em desenvolvimento retomam a igualdade subjetiva estabelecida formalmente como direito.

A dimensão corporal de cada indivíduo passa a ser considerada como argumento para propor e desenvolver ações políticas, em especial na educação escolar e na saúde. Sem desconsiderar que as discriminações geradas pela própria condição física e psíquica dos indivíduos foram um dos elementos que contribuíram para que os indivíduos se organizassem coletivamente em movimentos sociais, reivindicando melhores condições de vida e de participação na sociedade; é fundamental que sejam observadas e analisadas as formas e os conteúdos subjacentes às políticas de equidade.

Além disso, é imprescindível que áreas como a educação física investiguem o sentido educativo atribuído à formação humana a partir da consideração das diferenças empiricamente constatadas pela constituição corporal dos indivíduos.

4. Vinculado às teorias administrativas, a partir de 1990, concebe o corpo dos indivíduos na produtividade superando preocupações tradicionais da administração. Trata-se de um aprimoramento de técnicas de treinamento, que visam treinar os indivíduos dentro e fora das empresas, ampliando o campo de alcance e controle (HEROLD JUNIOR, 2009). 
Uma pergunta não pode deixar de ser formulada: no atual momento em que várias experiências com inclusão social são viabilizadas como forma de garantir direitos, qual a possibilidade da construção da igualdade substantiva por meio do acesso, por exemplo, à educação do corpo que se realiza pela educação física na escola?

\section{Equity: jottings for the education of the body}

ABSTRACT: The intention of the paper is to analyze the historic development of the idea of equality and its unfolding in policies of equity. During the analysis we tried to apprehend in which measure the science is constituted in contributes to justify an universal meaning of equality, and in contexts of inequalities, changing social inequalities for physical differences among individuals, taking bodily particularities as a reference.

KEYWORDS: Equity; equality; difference; body.

Equidad: apuntes para la educación del cuerpo

RESUMEN: El propósito de la exposición es analizar el desarrollo histórico de la idea de igualdad y sus despliegues en políticas de equidad. Durante el análisis intentamos aprehender en que medida la ciencia se constituye en aporte para justificar un sentido universal de igualdad, bien como en contextos de desigualdades, transfiere las desigualdades sociales para diferencias fisicas entre los individuos, tomando como referencia las particularidades corporales.

PALABRAS CLAVE: Equidad; igualdad; diferencia; cuerpo.

\section{REFERÊNCIAS}

ABBAGNANO, N. História da Filosofia. Volume 6. Tradução de António Ramos Rosa. 5. ed. Lisboa: Editorial Presença, 2000.

BANCO MUNDIAL. A equidade aumenta a capacidade de reduzir a pobreza. Washington, D. C.: BIRD/Banco Mundial. Relatório sobre o desenvolvimento mundial. (Press Release). Disponível em: <http://go.Worldbank.org/BS9QZ1YODO>. Acesso em: 10 out. 2008.

BANCO MUNDIAL. Relatório sobre o desenvolvimento mundial. Equidade e desenvolvimento. Washington, D. C.: BIRD/Banco Mundial, 2006. 
BOURGUET, M.N. O Explorador. In: ARASSE, D. et al. O homem do lluminismo. Lisboa: Presença, 1997. p. 207-250.

CORAGGIO, J. L. Propostas do Banco Mundial para a Educação: sentido oculto ou problema de concepção? In: DE TOMMASI, L.; WARDE, M. J.; HADDAD, S. (Orgs.). O Banco Mundial e as políticas educacionais. 2. ed. São Paulo: Cortez, 1998. p. 75-121.

FERRONE, V. O homem de ciência. In: ARASSE, D. et al. O homem do lluminismo. Lisboa: Presença, 1997. p. 157-182.

GÓIS JUNIOR, E.; LOVISOLO, H. R. Descontinuidades e continuidades do movimento higienista no Brasil do século XX. Revista Brasileira de Ciências do Esporte, Campinas, v. 25, n. I, p. 4I-57, set. 2003.

HEROLD JUNIOR, C. Do corpo-motor ao corpo-informação: corporeidade e trabalho no capitalismo. Revista Brasileira de Ciências do Esporte, Campinas, v. 30, n. 2, p. 107-122, jan.2009.

HOUAISS, A.; VILLAR, M. de S. Dicionário Houaiss da Língua Portuguesa. Rio de Janeiro: Objetiva, 2001 .

LOCKE, J. Segundo tratado sobre o governo. Tradução de Alex Marins. 2 ed., 3 reimpressão. São Paulo: Martin Claret, 2006.

PIERUCCI, A. F. Ciladas da diferença. São Paulo: USP/Editora 34, 1999.

RAWLS, J. Uma teoria da justiça. 2. ed. São Paulo: Martins Fontes, 2002.

ROUANET, S. P. O homem-máquina hoje. In: NOVAES, A. O homem-máquina: a ciência manipula o corpo. São Paulo: Companhia das Letras, 2003. p. 37-64.

SILVA, A. M. Corpo, ciência e mercado: reflexões acerca de um novo arquétipo de felicidade. Campinas: Autores Associados; Florianópolis: Editora da UFSC, 2001.

STOTZ, E. N.; ARAÚJO, J. W. G. Promoção da saúde e cultura política: a reconstrução do consenso. Saúde e Sociedade, São Paulo, v, 13, n. 2, p. 5-19, maio/ago., 2004.

Recebido: 14 abr. 2010 Aprovado: 17 jul. 2010

Endereço para correspondência:

Sissilia Vilarinho Neto Rua H-34, Qd. 77, Lt. 0 I - Conjunto Santa Fé Aparecida de Goiânia-GO CEP: 74.936-020 